ISSN: $1130-3743$

\title{
EPISTEMOLOGÍA NEOIDEALISTA Y FRACASO FUNDACIONAL DEL SABER EDUCATIVO
}

\author{
Neoidealist epistemology and constituent failure of the \\ educative knowledge
}

\section{Epistémologie néoidéaliste et échec fondationel du savoir éducatif}

Antonio J. Colom Cañellas y Juan C. Rincón Verdera

Universidad de las Islas Baleares. Departamento de Ciencias de la Educación. Campus Universitario. 07122 Palma de Mallorca. Correo-e: vdcejrvo@uib.es

Fecha de recepción: marzo de 2004

Fecha de aceptación definitiva: octubre de 2004

BIBLID [(1130-3743) 16, 2004, 19-47]

\section{RESUMEN}

En este artículo se revisa la aportación de la escuela neokantiana de Baden (principalmente la obra de Windelband y Rickert) así como la de Dilthey, culpabilizándoles de integrar a la Pedagogía en el seno de las ciencias de la cultura y de la historia, en ámbitos axiológicos y espiritualistas, lejanos a las concepciones organicistas que por aquel momento eran ya las propias de las otras ciencias humanas. Este discurso alejado de la realidad fáctica del educar no permitió una adecuada recepción de la obra de J. Dewey y a la larga supuso la desaparición de la Pedagogía en manos de la visión positivista de las ciencias de la educación. Se concluye evidenciando que el problema conceptual del saber educativo es más de carácter histórico que no epistemológico.

Palabras clave: neoidealismo, Rickert, Windelband, Dilthey, ciencias de la cultura y del espíritu, axiología, ciencias de la naturaleza, Teoría de la Educación. 


\section{SUMMARY}

In this article the contribution of Baden's neokantian school is revised, mainly Windelband and Rickert's work as well as that of Dilthey, who are blamed for integrating Pedagogy into the milieu of the sciences of culture and history, and in axiologic and spiritualist spheres, far from the organicistic conceptions which at that time already characterised the other humanistic sciences. This reasoning, far from the factual reality of educating, did not permit a suitable reception of $\mathrm{J}$. Dewey's work and in the end meant the disappearance of Pedagogy in the hands of the positivistic vision of education sciences. The article concludes by showing that the conceptual problem of educative knowledge is rather of a historical nature than an epistemological one.

Key words: neoidealism, Rickert, Windelband, Dilthey, sciences of culture and spirit, axiology, sciences of nature, Theory of Education.

\section{SOMMAIRE}

Dans cette article on revise l'aportation neokantienne de l'école de Baden (principalement de l'ouvrage de Windelband et Rickert) et aussi celle de Dilthey, afin de démontrer qu'ils sont qui integreron d'une manière indubitable à la Pedagogie dans les sciences de la culture et de la histoire, compris dans les limitations axiologiques et spiritualistes, loin des conceptions organiques, propres des autres sciences humaines et sociels. Cette discours, loin de la realité factique de l'éducation, il n'a pas permis une réception approprié de l'ouvrage de J. Dewey, ce qui, avec le temps suppose la disparition de la Pedagogie de la sphère d'influence du positivisme et son substitution pour les sciences de l'éducation. On s'arrive a l'évidence que le probleme conceptuel du savoir éducatif est plus une caractéristique historique que epistémologique.

Mots clef: neoidealisme, Rickert, Windelband, Dilthey, sciences de la culture et de le sprit, axiologie, sciences de la nature, Théorie de l'Éducation.

La problemática epistemológica del conocimiento educativo sigue, hoy en día, sin estar solucionada a pesar del interés que la cuestión suscita entre quienes se dedican a los estudios teóricos de la educación. Creemos que el origen de tal situación no se genera, ni mucho menos, en las tensiones actuales de la teoría de la ciencia, ya que, ciertamente, nos es difícil intentar desarrollar un aparato crítico de la epistemología pedagógica sin realizar una labor previa de investigación y de decantación histórica que creemos está aún por hacer. Hay unas cuestiones y unos años clave para ello, y es, a grandes rasgos, el pensamiento pedagógico desarrollado en Alemania, a partir de 1870, y que, si bien se siguió prolongando durante toda la primera mitad del siglo $\mathrm{xx}$, no pudo resistir la crítica de las primeras sistematizaciones de corte fenomenológico, allá por 1914.

Fue en la Universidad de Baden donde se conformó una escuela de pensamiento neokantiano, de corte radical — criticaban a los filósofos de la otra escuela kantiana de Marburgo de racionalistas y cientificistas- alrededor primero de $G$. Windelband y, después, de su sucesor en la cátedra E. Rickert, que junto con 
G. Dilthey, y después R. Eucken, conformaron el núcleo duro de una filosofía idealista que, a su vez, desarrolló un sentido espiritualista de las ciencias de la cultura. Pues bien, fueron estas ciencias del espíritu las que sirvieron de refugio epistemológico a la educación, y quienes la orientaron hacia la cuestión axiológica entendida como fundamento y razón del saber pedagógico, lo que sin duda alejó, aun más si cabe, a la Pedagogía del desarrollo teórico por el que se encaminaban las otras ciencias humanas, próximas a la concepción naturalista y organicista de la ciencia.

Así pues, se vio a lo educativo en relación a lo espiritual, lo que fue aprovechado para sus fines tanto por el catolicismo como por las iglesias reformadas acentuándose el discurso acerca de la idealización del hombre y de la educación, que se veía como instrumento para el logro axiológico, la Pedagogía se convertía en un discurso que, incluso, mostraba atisbos teológicos ${ }^{1}$; si su razón era la razón axiológico-espiritual, se impedía indagar en la materialidad — practicidad- del conocimiento educativo, por lo que, al mismo tiempo, se limitaba la posibilidad de aproximar la racionalidad educativa a la racionalidad propia de la ciencia.

Nuestra crítica se asienta pues en el hecho de que el pensamiento pedagógico de tales momentos ofertó unos planteamientos subjetivistas (asentados en creencias), y parciales (centrados en lo axiológico), que hicieron de la Pedagogía un arcaísmo del saber, al menos en el plano de la teoría del conocimiento; se estaba creando una corriente pedagógica que propiciaba un discurso, cada vez más alejado de la realidad fáctica, que se situaba en el mundo de la mera especulación idealista en oposición crítica al mundo de la naturaleza. De esta manera, en la génesis de la moderna epistemología pedagógica encontramos ya el fracaso fundacional de su propio saber, que es lo que intentaremos evidenciar, en esta ocasión, a partir de las principales aportaciones de algunos de los autores citados ${ }^{2}$.

\section{Guillermo Windelband: el lugar de la Pedagogía en el mundo de los valores UNIVERSALES}

Entre la Escuela de Marburgo y la Escuela de Baden pronto se dieron diferencias de hondo calado ya que en la primera se reducían los procesos subjetivos del

1. Este espiritualismo se hace radicalmente patente en la obra de EUCKEN (1925). Ya en el prólogo, el traductor de la misma afirma que para Eucken la "vida religiosa es sinónimo de vida espiritual". Para ampliar la cuestión y en especial la Pedagogía de carácter religioso, véase HovRE (1934).

2. Esta filosofía crítica neokantiana se concretará educativamente en el historicismo culturalista de Rickert, en el historicismo psicologicista de Dilthey y en las pedagogías especulativas de Eduardo Spranger, Herman Nohl, Guillermo Flitner, Jonas Cohn y Augusto Messer. Spranger, Nohl y Flitner son herederos directos del espiritualismo y el historicismo de Dilthey, elaborando pedagogías de tipo culturalista. Cohn y Messer reciben, directa o indirectamente, la influencia de la Escuela de Baden y, por lo tanto, están condicionados por las teorías axiológicas de Rickert, construyendo pedagogías centradas en los valores que emanan del ámbito de la comunidad cultural. 
conocer a los métodos objetivos que garantizaban, de cierta manera, la validez del conocimiento (dimensión lógica) (Messer, 1933, 84; Flamarique, 1991; Rose, 1991), mientras que en Baden se elaboró una filosofía o teoría de los valores (Schnädelbach, 1991) considerados independientes de los hechos psíquicos que los atestiguaban (dimensión axiológica). En este contexto, será Windelband, y posteriormente Rickert, quienes se encargarán de estudiar la esfera de la cultura humana objetiva ${ }^{3}$. Se trata de una vuelta crítica a la doctrina kantiana, condicionada por una interpretación del mundo histórico y cultural, o sea, por una ciencia histórica que precisa de un sistema de principios críticamente sólidos. Estos principios serán los valores, considerados como normas ideales de validez absoluta ${ }^{4}$. La filosofía de los valores será para Windelband la ciencia crítica de los valores universales (Cacciatore, 1993).

3. Desde el punto de vista teórico son fundamentales sus Preludios, en particular el ensayo La ciencia natural y la Historia, pues supone la esencia de su lógica de la bistoria, la sistematización de sus planteamientos epistemológicos. Ver WINDELBAND, G. (1947) La scienze naturali e la Storia, en Preludi. Saggi e Discorsi d'Introduzione alla Filosofia. Milan, Valentino Bompiani, 156-174.

4. Veamos cómo entienden el concepto de "valor" los principales representantes de la Escuela de Baden, objeto de nuestro artículo. Como sabemos, Platón equiparó al ser con el valor, pues las ideas formaban la verdadera realidad, o la realidad más valiosa. Pues bien, en Baden el valor es una cualidad pura que hace referencia al ser, de tal manera que el valor conforma un predicado del ser. Los valores son objetivos y absolutos, lo que no significa que sean hipótesis metafísicas de las ideas de lo valioso. Aquí la objetividad significa su autonomía en referencia a toda estimación subjetiva y arbitraria, de tal manera que lo que bien podríamos denominar "ontología del valor" no es un sistema de preferencias subjetivas, aunque tampoco es una metafisica de seres absolutamente trascedentes. Los valores, al ser intemporales, se confunden con las idealidades, pero su realidad no es la de ser ideal, ni tampoco la de ser real, sino la de valer. Desde esta perspectiva, para Windelband y Rickert la filosofía debe ser considerada una teoría de los valores donde se busquen los principios que garanticen la validez del conocimiento. Tales principios son los valores que constituyen el a priori y fundamento de la validez universal y necesaria de las ciencias. Así, por ejemplo, Windelband parte de la "norma", según la cual debe regirse toda la conducta humana. Ahora bien, las normas no son similares a las leyes naturales, no son principios para "explicar", sino principios para "valorar" lo que es bueno, bello o verdadero. Windelband da por sentado la existencia de valores universales, considerando que la filosofía es ala ciencia de los valores" (ciencia crítica). En este sentido, distingue entre "ser" y "deber ser", perteneciendo los valores al orden del deber ser, en el que la lógica, la ética y la estética son normativas ideales a las que se acomodan las conciencias, tanto en su ser como en su conocer. Por su parte, Rickert distinguió entre "norma" y "valor". La norma ordena realizar un valor, surgiendo aquélla cuando hay un valor al que se atribuye validez absoluta. Los valores no tienen realidad, pues sólo "valen" (de ellos no podemos decir ni que son ni que dejan de ser). Ahora bien, si entendemos las cosas es porque sobre ellas hay un mundo de valores que es trascendente a las cosas mismas, y que se nos ofrece como verdadera finalidad del conocimiento (sobre la esfera del ser encontramos la esfera del valor). El ser es posible mediante la conciencia trascendental, pero la rigurosa objetividad reside en la trascendencia de los valores, que, a su vez, la otorga a las cosas y a nuestro conocimiento sobre ellas. Así pues, no es posible hablar del sentido objetivo de los valores si no es en su sentido trascendente. Los valores no son un ser, pues sólo hay ser en la conciencia trascendental, sino un deber ser. La objetividad de la ciencia se fundamenta en la objetividad de los valores, a cuyo servicio está el entendimiento en su instancia más pura. La filosofía es, pues, un sistema para el conocimiento del mundo inteligible (la filosofía es la ciencia del valor). De otro lado, debemos decir que en la Escuela de Baden hay una tendencia a confundir los valores con los valores religiosos, siendo Eucken, una vez más, quien claramente expresa esta postura. No obstante, cabe citar a SCHELER $(1941,235)$, que al afirmar que no es posible una teoría pura de los valores se conforma con una teoría de la apreciación como máxima posibilidad. Véase WiNDELBAND $(1903,1960)$; 
Es en La ciencia natural y la Historia en donde Windelband elabora una teoría del conocimiento que le hace distinguir entre las ciencias de la naturaleza y las de la cultura en función de los fines que se proponen: mientras las ciencias naturales buscan una explicación de los fenómenos desde el punto de vista de las generalidades, intentando descubrir leyes que obedecen a hechos, las ciencias culturales buscan la explicación comprensiva de acontecimientos aislados por lo que tienen como objeto lo singular en su forma históricamente determinada. En el primer caso el pensamiento científico se dirá que es nomotético (generalizador), mientras que en el segundo es idiográfico (particularizante) (Windelband, 1947, 162-163). Como decíamos, las primeras generalizan los hechos como ejemplares típicos de una misma especie, pues tienen como objetivo final el reconocimiento de lo universal; las segundas son ciencias individualizantes que buscan comprender la forma de lo particular en la vida del hombre, de los pueblos, de las sociedades, en el desarrollo de su lengua, su religión, su educación, su ordenación jurídica o sus producciones culturales, literarias y artísticas, teniendo, por lo tanto, como objetivo final el reconocimiento de lo contingente (Windelband, 1947, 166). A las ciencias nomotéticas pertenecen todas las ciencias de la naturaleza, mientras que a las idiográficas pertenecen las ciencias culturales e históricas (Losee, 1989) 5 . Es decir las ciencias idiográficas actúan como si la temporalización del pasado estuviese situada idealmente en el presente. Dicho en otras palabras, la historia se dirige hacia lo que se puede intuir, mientras que la ciencia de la naturaleza tiende a la abstracción (Windelband, 1947, 163).

Desde esta perspectiva, intuición y abstracción nunca pueden subsumirse (reducirse una a la otra), pues el momento histórico (intuición) y el momento naturalista (abstracción) del saber humano no se dejan reducir, según Windelband, a una única fuente (Windelband, 1947, 170-173): la ley general y el suceso singular quedan uno al lado del otro como las últimas magnitudes inconmensurables de nuestras representaciones del mundo (Windelband, 1947, 174). En este sentido, podemos decir que la ciencia que estudia la fenomenología educacional (Pedagogía), al formar parte de la cultura humana, buscará el conocimiento de los sucesos singulares, es decir, procederá idiográficamente, alejándose entonces de las ciencias generalizantes, positivistas o experimentales. En consecuencia, la Pedagogía se centrará en la reflexión teorética y especulativa sobre los fines de la educación. Lo veremos a continuación. En tal contexto, la filosofía se interrogará sobre la existencia de una ciencia que tenga un valor absoluto y necesario de la verdad, si hay

RICKeRT (1910, 1915); SCHELER (1941, 235); ORTEGA y GASSET (1923); EuCKEN (1925), SCHuWERAR (1933); LARROYO (1942); FEDERICI (1933); NAVARRO (1962); MONCHO (2003); DujovNE (1959). Versiones más actualizadas de la cuestión podemos encontrarlas en CAMPS (1993), y con un planteamiento totalmente diferente en QuinTÁs (1989).

5. La distinción que establece Windelband (ciencias nomotéticas y ciencias idiográficas), no obstante, se ha de entender como puramente lógico-formal y metodológica, pues sobre un mismo objeto de la realidad puede, en ocasiones, actuarse por ambos procedimientos. 
una moral que tenga un valor absoluto y necesario del bien, y si hay un arte que posea un valor absoluto y necesario de la belleza. Por tanto, no será su objeto lo empírico - la realidad fáctica - sino las normas mediante las cuales el pensamiento, el querer y el sentir logran el valor de verdad a que aspiran (Windelband, 1947, 168-169). Desde esta perspectiva, la filosofía no elabora juicios de hecho, sino juicios de valor referidos siempre a una conciencia valorante. Ahora bien, tales juicios han de tener una validez universal en el sentido de que deben ser reconocidos; deber ser que es una necesidad ideal (indeterminismo, presencia de libertad), distinta de la necesidad natural (determinismo, ausencia de libertad). Esta idealidad configura una conciencia normativo-valorativa no fáctica, cuyas leyes no deben verificarse, necesariamente, en todos los hechos singulares (Messer, 1933, 14), pues se trata de normas a las que deben ajustarse todas las valoraciones lógicas, éticas y estéticas. La conciencia normativa, por lo tanto, es un sistema de normas (código axiológico) cuya validez no es sólo objetiva, sino que también poseen valor subjetivo.

En la determinación de la conciencia empírica por parte de la conciencia normativa se encuentra la libertad que siempre, en Windelband, nos remite a lo religioso (él lo denomina lo santo), en donde la conciencia normativa se evidencia trascendente y supramundana; $y$, en cuanto que absoluta, se erige en la guía de los valores de verdad, bondad y belleza. Ahora bien, en lo trascendente es real todo lo que debe ser y no lo es lo que no debe ser; por tanto, los juicios valorativos (universalidad) se distinguirán de lo subjetivo (relatividad) por su pretensión de validez absoluta (deber ser). Estos juicios valorativos adoptan tres formatos: lógicos, éticos y estéticos, dando lugar a las tres ciencias filosóficas fundamentales: la lógica, la ética y la estética. Para Windelband la lógica no es otra cosa que axiología, ya que, al igual que nos encontramos con normas éticas y estéticas que posibilitan, por su adecuación a ellas, el bien y la belleza, también hay normas lógicas que posibilitan, por su adecuación a ellas, la verdad. Enseñar esta verdad axiológica será, pues, el objeto último de la Pedagogía.

\section{ENRIQUE RICKERT Y LA LÓGICA DEL CONOCIMIENTO}

Rickert, siguiendo a Windelband, refrenda la distinción entre ciencias naturales y ciencias culturales, de forma muy parecida. Los objetos culturales se constituyen por referencia a los valores, mientras que los objetos naturales son ajenos a ellos. También se distinguen por el tipo de método que emplean: en las ciencias naturales se sigue el método naturalista (generalizador; procede por conceptos y leyes universales) y en las culturales, el método histórico (individualizador; quiere exponer la realidad en su singularidad). En este sentido, la Psicología no puede ser la ciencia modelo de las ciencias culturales, pues al estudiar la psique (naturaleza) debe proceder por el método generalizador, buscando leyes universales que expliquen los procesos mentales. La ciencia en la que deben reflejarse todas las ciencias 
culturales es la historia que quiere reflejar el pasado en el presente, en su individualidad y particularidad. En este sentido, es fácil deducir que la educación es un bien de cultura, un bien en el que residen valores; consecuentemente, la Ciencia de la Educación, la Pedagogía, se erige en una de las ciencias culturales y, como tal, debe investigar su realidad (objetos y procesos educacionales) con una metodología histórica (especulativa), alejándose del método científico y experimental.

Rickert ${ }^{6}$ al pretender definir y desarrollar los intereses, problemas y métodos comunes a las disciplinas que pertenecen a las ciencias culturales, elabora una lógica del conocimiento (teoría del método), a partir de la cual expone las dos formas fundamentales en las que se manifiesta la ciencia (Rickert, 1965, 25). Las ciencias pueden distinguirse por los objetos de que tratan (principio material) y por los métodos que aplican (principio formal). Rickert se opone a la clasificación de la ciencia que encuentra en los conceptos de naturaleza y espíritu su punto de demarcación. Por lo general, el significante naturaleza se refiere al ser corporal, y el de espíritu al ser anímico, y, de las peculiaridades que presenta el contenido de la vida psíquica en oposición con el contenido del mundo físico, se derivan las diferencias entre los métodos de ambas. De ahí, que junto a la Física, la más general y fundamental de las ciencias del cuerpo, sea la Psicología la ciencia más general y fundamental del espíritu (Rickert, 1965, 37-38). No es éste el camino correcto y en lugar de una distinción entre naturaleza y espíritu, la teoría del método debe establecer otras dos parejas de conceptos fundamentales para establecer el principio material de la ciencia empírica: los de naturaleza y cultura ${ }^{7}$.

Para Rickert naturaleza es el conjunto de lo nacido por sí, oriundo de sí y entregado a su propio crecimiento; enfrente se sitúa la cultura, sea como lo producido directamente por un hombre en función de fines valiosos, o si la cosa existe con anterioridad, como lo cultivado intencionalmente en atención a los valores que en ella residen (Rickert, 1965, 45-46). En todo objeto o proceso cultural hay siempre incorporado algún valor reconocido por el hombre, en función del cual lo produce o, si ya existe, lo cuida y cultiva de tal manera que si de un objeto cultural se retira el valor, éste queda reducido a mera naturaleza. En cambio, lo que ha nacido y crecido por sí, debe considerarse sin referencia a ningún valor. Es decir, en los objetos y procesos culturales residen valores, que llamaremos bienes, para distinguirlos, como realidades valiosas, de los valores mismos que no son realidades, sino idealidades valiosas (Dacal, 1995). Por tanto, es en referencia a los valores cuando distinguimos dos clases de objetos, los culturales y los naturales, y sólo por ese medio podemos diferenciar ambas clases de objetos (Rickert, 1965, 47-49).

6. Para el desarrollo de este apartado nos fundamentaremos, básicamente, en su obra (1965) Ciencia cultural y ciencia natural. Madrid, Espasa-Calpe, pues supone una síntesis perfecta de su pensamiento en lo referente al objeto de las ciencias culturales.

7. Sin embargo, al igual que Windelband, entiende que para la consideración lógica de la ciencia empírica aparecen territorios intermedios en los cuales están estrechamente unidas investigaciones que pueden ser culturales en su contenido y naturalistas en su método y viceversa. Ver íbidem, pp. 43-44. 
La palabra cultura tiene muchas connotaciones, siendo la que más equívocos produce la que señala como nota distintiva de lo cultural la manifestación de factores psíquicos, entendidos como la única limitación posible de los objetos culturales frente a los naturales (Cohn, 1944, 32), por lo que fácilmente la Psicología puede ser considerada como la base principal de toda ciencia cultural (Mardones y Ursua, 1982, 45). En cambio, Rickert piensa que el factor psíquico es condición necesaria, pero no suficiente, ya que si desaparece la referencia a los valores culturales, aunque haya actividad psíquica, no hay más que naturaleza en nosotros y en tal caso fallaría el criterio de clasificación (Rickert, 1965, 51-52). Otra cosa es que los procesos culturales deban considerarse, no sólo en relación a un valor, sino también a un ser psíquico que los valora (conciencia psíquica valorativa), y, en este sentido, lo psíquico se considera como lo más valioso en comparación con lo corporal; existe pues un nexo de unión en las oposiciones naturaleza/cultura y naturaleza/espíritu, ya que en los procesos culturales, en tanto que bienes valiosos, hay siempre una valoración, por lo que la vida psíquica también juega un papel importante (Bueno, 1978). Sin embargo, y pese a ello, no puede justificarse una división de las ciencias fundada en la oposición entre naturaleza y psique, pues la mera presencia de lo psíquico (naturaleza) no constituye por sí sola el objeto cultural ${ }^{8}$.

La realidad empírica se manifiesta como una pluralidad incalculable (complejidad) por lo que el conocimiento de lo real no puede ser nunca una reproducción (positivismo), sino una transformación simplificatoria de la realidad (Rickert, 1965, 59-60). La imposibilidad de aprehender en conceptos la realidad tal cual es, hace que Rickert subraye la irracionalidad de la realidad empírica, extrayendo dos principios de aplicación a todo objeto real que conozcamos inmediatamente: por una parte, en la realidad empírica todo fluye constantemente (principio de la continuidad de todo lo real); y, por otra, en la realidad empírica no hay nada absolutamente homogéneo porque todo es diferente (principio de la heterogeneidad de todo lo real). El principio de la heterogeneidad (diferencia) se combina con el principio de la continuidad (fluidez), encontrando en la realidad una continua diferencia, lo cual imprime el sello característico de irracionalidad (Rickert, 1965, 61-62). Sólo mediante una separación conceptual de la heterogeneidad y de la continuidad puede la realidad hacerse racional: se trata de transformar la continuidad heterogénea en discreción heterogénea. Si queremos mantener las cualidades de la realidad tendremos que atenernos a su heterogeneidad, para lo cual será preciso hacer cortes en su continuidad, poniendo límites a nuestro campo de investigación, aunque para ello simplifiquemos la realidad, pues perderemos todo aquello que esté fuera de lo acotado (Rickert, 1965, 63-65).

8. Rickert distingue conceptualmente entre la valoración, los valores y los bienes. En este mismo sentido ver los trabajos de FrondzI, R. (1977) ¿Qué son los valores? Introducción a la axiología. México, FCE, 60-73, y Ruger, R. (1969) La filosofía del valor. México, FCE. 
Para que no sean arbitrarias tales transformaciones, las ciencias necesitan un a priori o principio formal de selección para así acotar recíprocamente las realidades y en el que apoyarse para proceder a separar lo esencial de lo que no lo es (Rickert, 1965, 63-66). En este sentido, el conocimiento, en su aspecto formal, es el conjunto de lo esencial, nunca una reproducción del contenido de la realidad (esencia de las cosas). A la metodología le corresponderá poner de manifiesto, según su carácter formal, la manera en que se forman dichas esencias, pues el carácter del método científico dependerá del modo como se hagan los cortes en la realidad y se seleccionen las partes esenciales. En este sentido, la solución al problema de si entre los dos grupos de ciencias particulares empíricas hay diferencias metodológicas, coincidirá con la solución al problema de saber si hay también dos puntos de vista diferentes en el principio que utilizan para separar lo esencial de lo que no lo es y reducir a la forma de concepto el contenido intuible de la realidad (principio formal de la conceptualización). En definitiva, para comprender el método de una ciencia debemos estudiar el modo que tienen de proceder cada una de las ciencias empíricas particulares (Rickert, 1965, 67-68).

Para las ciencias naturales, la realidad se divide en lo físico y en lo psíquico, dando lugar a dos ámbitos separados de investigación y a dos sistemas de ciencias particulares generalizadoras: las que se ocupan de las realidades corporales y las que lo hacen de las realidades anímicas. Ambos sistemas son iguales en cuanto a su estructura lógica, y toda investigación de objetos y procesos corporales o espirituales (naturales) debe desarrollarse por el mismo procedimiento. Este proceder consiste en formar conceptos universales, a los cuales puedan subordinarse las distintas realidades empíricas. Lo fundamental será lo que tienen en común (general) todos los objetos y procesos que caen bajo el mismo concepto universal, mientras que lo que no sea común (particular) será considerado como no esencial y, por lo tanto, ajeno a la ciencia. Conocer la realidad significará descubrir leyes generales (universales), cuya esencia lógica incluya el no contener nada de lo que se encuentre sólo en los objetos y procesos singulares. Éste es el proceder propio de las ciencias naturales, es decir, de las ciencias que utilizan una metodología generalizadora. El modelo del primer tipo de ciencia empírica particular es la Física (mecánica), mientras que la Psicología lo es del segundo tipo. En este sentido, lo psíquico (naturaleza cuando no se refiere a valores) debe ser investigado por el método generalizador propio de las ciencias naturales, es decir, estableciendo conceptos universales y elaborando leyes generales (Rickert, 1965, 80).

Lo cierto es que la realidad es más compleja (incalculable) de lo que piensa el proceder positivista que sólo ve realidades físicas y psíquicas que son; obviando la dimensión axiológica, donde las normas ideales valen (Rickert, 1965, 84-85; Cuéllar, 1998). El hombre al ser capaz de establecer valores evidencia ya que la consideración generalizadora no es suficiente, por lo que no es lícito investigar la realidad sólo por el método naturalista. Si lo hiciéramos no nos quedaría más remedio que suprimir la referencia a los valores, que son los que individualizan la realidad, haciéndola irrepetible. Con esto, sin embargo, no se demuestra que la vida 
anímica, como tal, se oponga a entrar en una concepción naturalista, sólo se demuestra que determinadas especies de la vida anímica, por la significación que en ellas reside (los valores), no pueden tratarse únicamente por el método generalizador. Lo que le importa a Rickert es mostrar que la ciencia que investiga la vida anímica (y no corporal), cuando entran en juego los valores, no puede investigarse por el método naturalista o generalizador, que no capta la peculiar individualización de los objetos culturales. Aquí, precisamente, reside el problema de la ciencia cultural (Rickert, 1965, 85).

La ciencia necesita un principio directivo para la selección de lo esencial. En las ciencias naturales, tanto si se investiga lo físico como lo anímico, este principio consiste en la composición de lo común mediante comparación empírica y su exposición mediante leyes generales. Su problema se reduce pues a encontrar los conceptos universales o leyes naturales a que se subordinan sus objetos. Ahora bien, si ha de haber para el mundo real, dentro de la investigación particular, un modo de conceptualización que se diferencie del que emplea la ciencia natural, no es posible asentarlo sobre las propiedades de la vida psíquica. Lo cierto es que hay ciencias que no se proponen formar conceptos universales, tales como las ciencias históricas que quieren exponer su parcela de la realidad (que no es general, sino particular) en su individualidad, gracias a la referencia a los valores universales. Tan pronto como la individualidad entra en consideración falla el concepto naturalista, porque su significación consiste en separar y excluir lo individual por no ser esencial, perdiéndose toda la riqueza que supone lo único e irrepetible, propio de las ciencias históricas y culturales. Si sólo se procediera por el método naturalista generalizador la ciencia no cumpliría su principal cometido que no es otro que el progreso de la humanidad, pues no captaría la realidad en toda su complejidad (Rickert, 1965, 87-88).

Ahora bien, para Rickert, naturaleza e historia no son dos realidades distintas, sino la misma realidad vista desde dos puntos de vista diferentes. La realidad se hace naturaleza cuando la consideramos con referencia a lo universal (ausencia de valores); y se hace historia cuando la consideramos con referencia a lo particular e individual (presencia de valores). En consonancia con ello, opone al proceder generalizador de la ciencia natural el proceder individualizador de la historia (Rickert, 1965, 91-92). Las ciencias empíricas tienen todas en común el hecho de formular juicios verdaderos sobre el ser real del mundo sensible, con lo cual sólo puede haber una ciencia empírica unitaria referida a la realidad, que también es única. Ahora bien, las ciencias particulares de la realidad proponen, igualmente, dos fines diferentes en la forma de la generalización y de la individualización y, para conseguir tales fines, requieren de modos de conceptualización diferentes en la forma. En este sentido, la educación es un bien de cultura, es decir, un bien en el que residen valores; consecuentemente, la Ciencia de la Educación, la Pedagogía, como ya sucedía en Windelband, se erige en una de las ciencias culturales y, como tal, debe investigar su realidad empírica (objetos y procesos educacionales) con 
una metodología histórica (especulativa), procediendo por individualización, alejándose del método científico y positivista propio de la ciencia natural.

\section{Guillermo Dilthey y El CONOCER DE la CienCia}

La estructura interna del pensamiento de Dilthey puede sintetizarse en dos puntos: por una parte, la visión y comprensión de la vida como una totalidad (conjunto finalístico); $y$, por otra, la historicidad de todas las producciones del espíritu humano (espíritu objetivado)9. El objeto de las ciencias del espíritu es la realidad histórica y social (mundo histórico), que está formada por individualidades que sólo pueden ser conocidas por el método hermenéutico, el cual busca hacer comprensible y viva la unidad de la vida. Tal objeto no puede ser captado por los instrumentos de las ciencias de la naturaleza, sino con los propios de las ciencias del espíritu. La comprensión es la operación intelectual de estas últimas y se distingue

9. Veamos en qué sentido debemos interpretar el concepto de "espíritu" en nuestros autores. La acepción filosófica de "espíritu" es plural y compleja; asi en la escolástica sería forma o sustancia viviente inmaterial; en el contexto empirista — Berkeley, por ejemplo - hablaría más bien de inmaterialidad, y en Bergson se trataría del "yo interior profundo". No obstante, el sentido de "espíritu" o de "espiritual" en la Escuela de Baden se nos presenta más próximo como consecuencia de la unificación que de la "idea" y el "espíritu" realiza Hegel, de tal manera que llega a afirmar que "la idea es el aspecto abstracto del espíritu", por lo que en este autor el espíritu es una realidad concreta y viviente. Además, el espíritu lo es todo, o mejor dicho, la Verdad del todo, por lo que tiene categoría de "universal". Pues bien, la "fenomenología del espíritu" vendría a ser el estudio de este autodespliegue ya que el ser y la naturaleza son también espíritu en cuanto camino hacia la autorrealización del propio espíritu; de ahí que ambos - ser y naturaleza - sean denominados "espíritu subjetivo". Por el contrario, el "espíritu objetivo" sería el espíritu subjetivo encarnado en la moralidad, el Estado y la historia, mientras que el "espíritu absoluton sería el autodesarrollo del espíritu en el arte, la religión y la filosofía. Bajo este contexto, cabe decir que tanto Windelband, Rickert como Dilthey se preocupan por el espíritu objetivo, o si se quiere, por las objetivizaciones espirituales, en cuya consecución la educación jugaría un papel primordial. En todos estos autores el espíritu se trata de una realidad viviente y activa. Sin embargo, Dilthey, aunque próximo al concepto hegeliano de espíritu objetivo, presenta una diferencia fundamental, pues mientras para Hegel el espíritu objetivo es un camino "racional» hacia la suprema realidad del espíritu (espíritu absoluto), en Dilthey el espíritu es un único complejo, no inferido ni investigado por el pensamiento, sino "vivido" (la vida toda), punto de articulación de las vivencias individuales, históricas y sociales. Dilthey, en definitiva, en lugar de la "razón universal" hegeliana pone la "vida" en su totalidad, la vivencia, la comprensión, la conexión histórica de la vida con todas sus irracionalidades. En este sentido, en Dilthey las que denomina "ciencias del espíritu" son un grupo de ciencias caracterizadas por el método científico espiritual o método de validez universal que se sustenta en la Psicología, pues permite comprender al hombre como entidad histórica, llegándose así a la objetivización ideal. De otro lado, debemos decir que el radicalismo espiritualista de Baden llega a expresarse sin tapujos de ningún tipo en la obra de R. Eucken al afirmar que la vida espiritual es la vida religiosa. Para fundamentar estos aspectos, así como alternativas de ampliación, ver: GADAMER (1988, 277-304); IMAZ (1978, 199-239, 307 y 308); Marias (1944), Ortega y Gasset (1923, 1927, 1933-1934); Schrödinger (1956); Díaz de Cerio (1957, 547565); GABILONDO (1988, 147-154); FaRRÉ (1974, 115-116); así como los trabajos más ilustrativos de los autores citados: HeGel (1935), WindeLBAND (1910); RICKERT (1923, 1925-1929); DILTHEY (1978c, 170-176); SPRANGER (1923) y EUCKEN (1925). 
de la explicación, que es la propia de las ciencias de la naturaleza, porque explicar es establecer conexiones causales entre los objetos de la experiencia externa, mientras que comprender es una forma de simpatía con un hecho histórico a partir de la vivencia de sus valores. Precisamente por ello, a la Psicología explicativa de las ciencias naturales se opone la Psicología comprensiva propia de las ciencias del espíritu, que se convierte en la ciencia modelo para el estudio e investigación del mundo espiritual. La explicación causal y la comprensión axiológica, lejos de oponerse, se necesitan mutuamente para entender la totalidad del mundo espiritual. En Dilthey, teleología, perfección y desarrollo son las claves de la vida anímica. La Pedagogía, apoyada en la Psicología comprensiva, debe dilucidar el camino que ha de seguir la educación para que el hombre se oriente teleológica y perfectivamente, conforme a los valores universales del conocimiento histórico.

Dilthey ${ }^{10}$ quiere llevar a cabo, por una parte, una clara distinción entre las ciencias de la naturaleza, cuya tarea es la explicación de la realidad natural, y las ciencias del espíritu, cuya tarea es la comprensión de la realidad espiritual (Martín López, 1976; López Moreno, 1990; Bambach, 1995); y, por otra, pretende establecer el método y la naturaleza de las ciencias espirituales. Así, su crítica de la razón histórica buscará, de un lado, analizar los caracteres propios de las ciencias históricas (Brie, 2000), remontándose hasta las formas y categorías del espíritu que actúan en el conocimiento histórico (concepciones del mundo ${ }^{11}$ y tipos fundamentales ${ }^{12}$ ) y, de otro lado, querrá hacer con la metafísica de la historia una operación análoga a la que había llevado a cabo la dialéctica trascendental para con la metafísica de la naturaleza, asumiendo de Kant la exigencia de la validez universal del saber mediante determinaciones axiológicas y normas de obrar según fines de validez universal (Dilthey, 1978a, 123-384). Sin embargo, Dilthey también se siente ligado al positivismo que impera en su época y, por ello, la fundamentación de las ciencias históricas no será apriorística (Grondin, 1989), independiente de la experiencia, sino basada en la experiencia concreta (interior) de los sujetos históricos. Dilthey, en última instancia, acaba disolviendo las ciencias de la naturaleza en las ciencias del

10. La parte más interesante de la investigación diltheyana está dedicada a la metodología de las ciencias del espíritu.

11. Los distintos paradigmas o cosmovisiones desde los que interpretar la realidad: religiosa, poética y metafísica. Ver DilThey, W. (1978b) Teoría de la concepción del mundo. México, FCE, 24-38. Ver también NoHL, H. (1965) Antropología Pedagógica. México, FCE, 286-287.

12. Únicas formas generales en las ciencias del espíritu que se originan a partir de las cosmovisiones del mundo, mediante una síntesis de los elementos singulares comunes: naturalismo, idealismo subjetivo e idealismo objetivo. El objeto del comprender, operación cognoscitiva fundamental en el campo de las ciencias del espíritu, es la individualidad, pero como ésta no puede alcanzarse si no es a través de la generalidad, es necesario recurrir a la forma del tipo que es el término medio entre la uniformidad y el individuo. Esta noción le sirve a Dilthey para definir el objetivo de las ciencias del espíritu: unir en un sistema la constatación del elemento común, en un campo determinado, con la individuación que en el mismo se realiza (comprender la individualidad a partir de la uniformidad sobre la cual la misma se destaca). Ver Teoría de la concepción del mundo, op. cit., 109-146. 
espíritu, entendidas como el mundo interior de la conciencia (Dilthey, 1978a, 341353). Se trata, por lo tanto, de sustituir la posición metafísica (Dilthey, 1978b, 38) por el punto de vista gnoseológico de la filosofía trascendental con un marcado carácter vitalista e historicista (Dilthey, 1978c, 79-87).

Todos los desarrollos metodológicos de Dilthey presuponen una concepción filosófica que considera la vida como una realidad radical, irreductible a cualquier otro tipo de realidad y sólo comprensible desde sí misma (Stefanovics, 1961). Su sistema filosófico descansa en la vida misma y en las posiciones que el hombre adopta ante los problemas que surgen de ella (concepciones y cosmovisiones). De esta forma, la Filosofía es una hermenéutica de la vida: la vida es tan rica y dialéctica que no puede ser comprendida a través de categorías estáticas y apriorísticas, sino sólo cuando se construye comprensiva y vivencialmente a través de categorías dinámicas y aposteriorísticas (Paez, 1988). En la vida se funden en un todo global el hombre, su mundo y su historia, porque la vida es una unidad sustancialmente histórica; la historia es la vida concebida desde el punto de vista del todo de la humanidad con la que forma una conexión unívoca ${ }^{13}$. Por tảnto, el centro del pensamiento de Dilthey es el concepto de vida, por lo que la reflexión filosófica ha de abordar los problemas de la vida con un tratamiento histórico, pues lo que el hombre es o haya de ser lo experimenta sólo por medio de los productos culturales históricos que se han objetivado en la vida. En base a ello podemos decir que para Dilthey toda comprensión es comprensión histórica, o capacidad del hombre para conocerse a sí mismo, a su mundo social y a su historia (Dilthey, 1978a, 117-120).

El conocimiento de las ciencias del espíritu se fundamenta en la conexión de las tres operaciones básicas del mundo espiritual (Imaz, 1978, 12): la vivencia, la expresión de vivencias y la comprensión de las expresiones vivenciales. La vivencia, que es la experiencia vivida de los objetos y procesos espirituales y, por lo tanto, la base de las concepciones del mundo (Dilthey, 1978b, 112-114; Spranger, 1948, 297), puede adoptar, en función de las tres dimensiones estructurales de la vida (conocimiento, estimación y voluntad), tres formas (Dilthey, 1978c, 50-79): cognoscitiva (conocimiento científico-objetivo), afectiva (estimación de los valores), y volitiva (dirección de la voluntad). La conexión de todas las vivencias configura la estructuralidad del vivir total. Todas las vivencias se manifiestan en la expresión (materialización de las vivencias en los objetos y procesos espirituales) y éstas sólo pueden ser entendidas mediante la comprensión (interpretación hemenéutica). Por tanto, las distintas concepciones del mundo que dan lugar a las diferentes interpretaciones de la realidad se configuran en torno a la triple dimensión de la estructura de la vida: el conocimiento objetivo, la estimación de los valores y la acción de la voluntad (Dilthey, 1978b, 156-157). Todas las concepciones del mundo contienen esta misma conexión estructural (Dilthey, 1978b, 115-117): el significado del mundo

13. La psicología de Dilthey es una teoría de la conexión estructural. Ver DilTHEY, W. (1978c) $E l$ mundo bistórico. México, FCE, 29 y 78. 
se decide sobre la base de una imagen de él (conocimiento objetivo), a partir de la cual se deduce el ideal supremo (estimación de los valores), y se direccionan nuestras actuaciones mediante normas de conducta orientadas por el ideal (dirección de la voluntad). Como la conexión estructural se desarrolla en condiciones cambiantes (históricas), también las concepciones del mundo, así como los tipos de hombres que conciben la vida y sus visiones de la realidad, han de ser diferentes, pues cada época imprime su sello particular (historicismo).

La vivencia, la expresión de vivencias y la comprensión de toda clase de expresiones vivenciales, fundamentan todos los juicios, conceptos y conocimientos que son propios de las ciencias del espíritu (Dilthey, 1978c, 91-97). En este sentido, la autonomía de las ciencias del espíritu frente a las ciencias de la naturaleza se basa: por una parte, en la peculiaridad de la percepción de su contenido (mundo histórico objetivado), ya que los hechos espirituales, a diferencia de los fenómenos investigados por la ciencia natural, son realidades percibidas de modo inmediato (no son externos al sujeto); y, por otra, en el método empleado por una y otra clase de saber científico, pues si la explicación (la reducción de cualidad a cantidad y enlace mediante leyes) $)^{14}$ es la metodología empleada por las ciencias de la naturaleza, la comprensión lo es de las ciencias del espíritu (el continuo de la vivencia, la expresión de vivencias y su comprensión empática) (Dilthey, 1978d, 360). Por tanto, el conocimiento del mundo espiritual en que sus fenómenos no pueden reducirse a elementos objetivos, se integra en el conocimiento del mundo histórico, que es quien responde a normas de carácter particular que dependen, a su vez, de la intuición, del entender y del pensamiento conceptual, es decir, del conocimiento contingente (Mallorquín, 1999; Moya, 1982).

En este contexto, Dilthey entiende que no se puede aplicar a las ciencias del espíritu la Psicología explicativa y causal propia de las ciencias de la naturaleza, sino que es preciso elaborar una nueva Psicología que sea descriptiva, comprensiva, analítica y no causal, que se adapte a la singularidad de las ciencias del espíritu, escapando, de esta manera, a cualquier forma de monismo epistemológico (naturalización de las ciencias del espíritu). Las ciencias del espíritu difieren de las ciencias de la naturaleza en que intervienen valores, fines y aspectos que no podemos simplemente explicar (cosmovisiones, creencias, ideologias, concepciones, religiones, etc.), sino que también debemos interpretar comprensivamente. A lo causal (causa-efecto) del mundo natural hay que oponer la comprensión y el sentido (libertad), que es, precisamente, lo que confiere identidad a las ciencias del espíritu. En la Psicología mecanicista explicativa no hay espacio para la libertad y la contingencia, característica fundamental del hombre y de las ciencias que lo

14. Según Collingwood, R. G. (1956) The Idea of History. Nueva York, Oxford University Press, 126-127, el positivismo "[...] primero descubre los hechos; segundo; establece leyes. Los hechos son inmediatamente descubiertos por la percepción sensible. Las leyes son establecidas por medio de la generalización de estos hechos a través de la inducción". 
estudian. Pese a ello, Dilthey, al igual que sucedía en Windelband y en Rickert, no descarta la Psicología explicativa porque como el hombre es un ser psicobiológico, también es posible explicarlo causalmente en lo que tiene de biológico, de natural, aunque sin caer en reduccionismos, puesto que lo espiritual en el hombre (lo antropológico, lo axiológico y lo teleológico), lejos de poder ser explicado mediante leyes generales debe ser comprendido empáticamente. Ahora bien, la comprensión no puede privar a las ciencias del espíritu de su dimensión explicativa, es necesario, por lo tanto, integrar explicación y comprensión, sin sacrificar ni lo uno ni lo otro (Dilthey, 1978a, 22-28; Nohl, 1965, 25-27).

La crítica a la razón histórica diltheyana quiere articular correctamente la razón teórica (implica una concepción de la objetividad que se mueve por el principio del determinismo, es decir, de causa-efecto) y la razón práctica (centrada en las categorías que emanan de la libertad). Dilthey entiende que estas dos formas de racionalidad encuentran su integración en el nexo de unión en el que el acontecimiento histórico (fenómeno natural sujeto a las variables de espacio y tiempo) sólo es comprensible bajo las categorías de la libertad. Se trata de la unidad de la razón dentro de un sistema crítico (Tuttle, 1994). Este nexo de unión lo encuentra Dilthey en la Psicología comprensiva; con lo cual, al encontrar el principio de unidad en una de las ciencias del espíritu, tales ciencias proclaman su autonomía frente a las ciencias de la naturaleza (autonomía que se hace más sólida al renunciar la Psicología a cualquier forma metafísica). Esta nueva Psicología descriptiva y comprensiva tiene por objeto las regularidades de la vida psíquica; como Psicología descriptiva procede por la observación de las individualidades a través de la percepción de nosotros mismos y de los otros, sobre todo de las personalidades tipológicas, describiendo sus uniformidades y sus diferencias (dialéctica de lo singular y lo general). La Psicología descriptiva se ha de extender, según Dilthey, a una Psicología comparada (Dilthey, 1978d, 285-310) que estudie las diversidades de la vida psíquica, utilizando los productos objetivos de la vida psíquica en la historia', es decir, por medio del lenguaje, el mito, la literatura, el arte, la educación y, en general, todas las realizaciones históricas.

La historia no es independiente de la experiencia, sino todo lo contrario, ya que está basada en la experiencia concreta (interior) de los sujetos históricos (es la gran diferencia entre la epistemología de Windelband y Rickert y la de Dilthey). Se trata de hacer valer los derechos de la experiencia en el origen de los conceptos, como ya había hecho en su momento el empirismo. Sin embargo, Dilthey no quiere caer en el reduccionismo empirista, y reducir su teoría a las impresiones particulares del sujeto que conoce. Se trata, a diferencia del empirismo, de partir del sujeto entendido en su globalidad, del sujeto en tanto que conjunto psíquico, que es el verdadero objeto de la Psicología descriptiva y que constituye, por lo tanto, la base de todo conocimiento. Para Dilthey la diferenciación entre ciencias de la naturaleza y ciencias del espíritu no se reduce a una simple diversidad de orientaciones metodológicas (método generalizante versus método individualizante), ni tampoco supone una heterogeneidad sustancial entre dos clases de objetos (objetos 
naturales y objetos espirituales); es mucho más que todo esto, ya que se trata de una dualidad de puntos de vista (perspectivismo) que siempre conduce, por una parte, a un posicionamiento en función de determinados intereses o criterios de selección del objeto por parte del sujeto; y, por otra, a la posibilidad de que se pueda localizar en el objeto un contenido específico que sea significativo para la ciencia. En este sentido, Dilthey afirma que las ciencias del espíritu sólo tienen un horizonte que las limita: la comprensión. La comprensión, por lo tanto, es el criterio de demarcación de las ciencias del espíritu frente a las ciencias de la naturaleza y, al mismo tiempo que define el objeto de aquéllas, configura la lógica que las rige y la metodología que les es propia (Dilthey, 1978c, 256-257).

Esta diferencia fundamental de contenido de las distintas ciencias implica una diferencia gnoseológica en función del modo como estos dos grandes sistemas de contenidos nos son dados: la percepción externa da acceso a los objetos físicos, fundamentando el conocimiento de lo natural; y la experiencia interna da acceso a los objetos espirituales, fundamentando el conocimiento de lo espiritual (Dilthey, 1978c, 210-238). Lo que Dilthey trata de establecer es el modo como se lleva a cabo la individualización de una determinada forma particular de vida, a partir de la generalidad de las verdades de la vida humana, social e histórica (espíritu objetivado) ${ }^{15}$. La caracterización de las ciencias del espíritu es la constante combinación de semejanzas generales con la singularización que de aquéllas se puede conseguir (combinación de teorías generales y estudio comparativo). Se parte de la unidad psicofísica de la vida humana, sin separar la significación que el hombre da a su existencia a través de la concepción que tiene del universo. De esta manera, captamos las cosas, simultáneamente, por medio de la observación interior (autoobservación) y de la observación exterior (las creaciones del hombre, la cultura), sin que sea posible ser espectadores puros, pues somos un producto de la historia y, consecuentemente, no es posible situarnos desinteresadamente ante nuestro objeto de estudio e investigación. En las ciencias del espíritu lo singular constituye el fin último de la investigación con igual rango que lo general (Dilthey, 1978a, 35-36). Como vemos, el conocimiento de la realidad exige la combinación de la Psicología explicativa (observación externa) y la Psicología comprensiva (observación interna).

La metodología comprensiva de las ciencias del espíritu ha de ser analítica, pues el análisis es el que descubre en las individualidades psicofísicas los elementos de que están construidas la sociedad, la cultura y la historia. El análisis consiste en la percepción interna (comprensión) de los objetos espirituales, es decir, el proceso que eleva las percepciones externas (explicación) a la conciencia del yo (operación individual), enlazándolas con la totalidad de la vida. Ahora bien, en la sociedad humana la entidad viviente que se nos da es el hombre mismo en sus

15. El espíritu objetivado consiste en el conjunto de productos culturales (idioma, costumbres, familia, religión, arte, filosofía, educación, etc.), que fueron antes espíritu subjetivo, vida espontánea en perpetua transformación y movimiento. Véase FLITNER $(1935,55)$. 
relaciones con los otros hombres y con los objetos de la realidad. Contra el individualismo entiende Dilthey que no se puede aislar al individuo e intentar construir la sociedad por yuxtaposición mecánica de individuos, pues el hombre no puede ser comprendido si se le abstrae de los diversos sistemas civilizatorios en los que se mueve (conjuntos interactivos) ${ }^{16}$. El hombre que la ciencia analítica ha de tomar por objeto de estudio es el ser humano integrante de la sociedad, en sus relaciones sociales (Dilthey, 1978a, 38-44). Ahora bien, el hombre, pese a ser un ser social, posee una existencia autónoma y un desarrollo particular gracias al valor y al fin que realiza en la sociedad, por lo que la aplicación del proceso comprensivo debe hacerse extensible también a los comportamientos individuales, de los que el fenómeno social es el efecto emergente. En este sentido, podemos decir que conocer un elemento de la realidad espiritual como significativo consiste en pensarlo como parte de una totalidad de la que recibe, precisamente, su sentido, al tiempo que la totalidad se manifiesta a través de todos y cada uno de sus elementos (conexiones dinámicas) ${ }^{17}$.

Desde esta perspectiva, la explicación y la comprensión se requieren como las dos caras de una misma moneda. La explicación debe dirigirse a la totalidad, la cual se comprende, una vez realizado el análisis en los conjuntos particulares que contiene, como una realidad total inseparable de sus partes pero que, a la vez, comprende estas partes a partir de las relaciones que mantienen entre ellas y con el todo. El hecho de

16. Para ilustrar la idea de conjunto interactivo podemos recurrir al siguiente ejemplo: un profesor, con independencia de la función que ocupa en el espacio docente, pertenece a diversos conjuntos interactivos: actúa en interés de su esposa e hijos, es decir, en beneficio de su familia; cumple una actividad económica y fiscal; ejerce sus funciones cívicas y políticas; puede estar sindicado y colaborar activamente en el sindicato; puede también pertenecer a un colectivo preocupado por la conservación del medio ambiente; y puede ser que, además, tenga como bobby la construcción de maquetas en miniatura. De este modo los individuos se hallan enteramente ligados a un conjunto interactivo y lo que constituye la base de cada uno de estos sistemas son las personas que se orientan a través de los valores y los fines que persiguen. El hombre posee plena autonomía, sin embargo, sólo es comprensible en el contexto social en el que se mueve y desarrolla.

17. Una categoría fundamental de la razón histórica es la conexión dinámica que se distingue de la conexión causal de la naturaleza en que produce valores y realiza objetivos. Dilthey establece como conexiones dinámicas: los individuos, las instituciones, las comunidades, las civilizaciones, las épocas históricas, y la misma totalidad del mundo histórico (la vida), que está constituida por un número infinito de conexiones estructurales. El rasgo característico de la estructura es la autocentralidad: toda estructura tiene su centro en sí misma. El individuo, el sistema cultural y toda la comunidad tienen en sí mismos su propio centro en el que están ligados, constituyendo la interpretación de la realidad, la valoración y la producción de los bienes. Esta autocentralidad establece una relación entre las partes y el todo que le dan significado, el cual sólo puede ser alcanzado a través de los distintos valores y objetivos en torno a los cuales tiene su centro. Cada época forma un horizonte cerrado y los individuos que viven en ella tienen la misma medida de sentir, de entender y de obrar. La significación de cada parte de una totalidad es sólo determinable en el sistema total de la época. Los valores culturales, morales, sociales, no serán fijos, no serán firmes y universalmente válidos, sino que variarán con los cambios de la historia (relativismo): sólo la vida es un Absoluto y la historia tiene una finalidad inmanente en sí misma. Véase El mundo bistórico, op. cit., 262 y 270. 
que en los fenómenos humanos aparezcan elementos que no pueden ser reducidos a lo mecánico, como son las intenciones, las deliberaciones o las decisiones, no significa que haya que renunciar a la explicación causal. De hecho, todos estos factores constituyen, en relación al acontecimiento, antecedentes y, por lo tanto, causas que pueden y deben ser explicadas. Sin embargo, el verdadero conocimiento de las ciencias del espíritu exige, además de la explicación, la comprensión, es decir, la relación entre la experiencia vivida, su objetivación y la comprensión, por lo cual el conjunto de lo vivido, de lo expresado y de lo comprendido es el método específico por el que la humanidad existe para el hombre. Ninguna ciencia del mundo espiritual puede existir sin esta referencia a la experiencia vivida porque los hechos espirituales tienen un sentido, y no pueden ser tratados como simples objetos, dando lugar exclusivamente a procesos de observación y experimentación que, por medio de la neutralización de la vivencia del que observa, se situarían dentro de un conjunto de secuencias mecanicistas. El sentido del objeto de las ciencias del espíritu no puede observarse, sólo puede vivirse.

\subsection{La Pedagogía y las ciencias del espiritu}

La educación, actividad mediante la cual los adultos tratan de formar la vida anímica de los seres en desarrollo (todo lo axiológico orientado a un fin), es una pieza clave en este espíritu objetivado. Para Dilthey, en clara oposición a los planteamientos herbartianos, no es posible una ciencia pedagógica ${ }^{18}$ con validez general que partiendo de los fines quiera extraer las reglas y metodologías para su actuación. No es posible expresar en conceptos de validez general tendencias que surgen de lo más profundo del espíritu humano (valores que son ordenados por la inteligencia de acuerdo con la estructura teleológica de la vida). Si el fin último de la vida es una representación trascendente que nunca puede ser expresada en conceptos de validez universal, el fin de la educación no puede ser reducido a ninguna fórmula ideal (Díaz de Cerio, 1961). Todo sistema histórico de la Pedagogía que haya sido eficaz ha estado condicionado por su proceso evolutivo, por su historicidad (Dilthey, 1968, 11-12). Por tanto, en educación lo máximo que se puede hacer es destacar un número limitado de principios universales a fin de derivar normas y reglas particulares de actuación, adaptadas a la circunstancia histórica (Dilthey, 1965, 30). La Pedagogía tiene por objeto descubrir lo finalístico en el hombre, estudiar su estructura teleológica. Para Dilthey este principio teleológico básico,

18. Dilthey considera que la Pedagogía es una de las ciencias del espíritu caracterizada por la comprensión, la valoración y la práctica, insistiendo excesivamente en este último aspecto. Para Dilthey la Pedagogía había atravesado tres etapas: primera, precientífica, al fundamentarse en la política, en la filosofía o en la teología; segunda, científico-natural (realismo, naturalismo y positivismo pedagógico); y tercera, científico-espiritual (la Pedagogía consigue su autonomía al insertarse dentro de las ciencias del espíritu). Véase Dilthey (1965). 
que es el propio principio vital, no es otra cosa que la conservación y exaltación de la especie y de todos y cada uno de los individuos de la misma (Dilthey, 1965, 31-33). La Psicología comprensiva, su hermenéutica de la vida, debe estudiar esta conexión teleológica y descomponer causalmente cada una de sus partes (explicación causal) para poder extraer normas que, no obstante, deberán contextualizarse históricamente o, si se quiere, experimentarse y demostrarse personalmente a posteriori (comprensión histórica).

Dilthey acaba subordinando la educación y su reflexión teórica a la propia vida, a una Filosofía vitalista de corte histórico y psicologicista. El resultado final de todo ello es la autognosis o autoconciencia, en que se resuelve la conexión interna de todos los conocimientos históricos y, entre ellos, el pedagógico. La Filosofía ha de buscar la conexión interna de sus conocimientos en el hombre y en lo que se ha objetivado en la vida (Dilthey, 1978c, 229-252). No hay fines educativos universales, no hay Pedagogía con validez general, y ésta acaba resolviéndose en un cúmulo de estructuras teleológico-axiológicas que sólo nos pueden aportar unos mínimos principios orientadores sustentados en una especie de darwinismo espiritual (supervivencia de los pocos valores y principios que pueden adquirir rango de universalidad). En Dilthey la teoría de la educación, por lo tanto, acaba sustentándose en la idea, en las creencias particulares de los individuos, en definitiva, en una filosofía de la vida y en su metodología hermenéutica o crítico-comprensiva. Lo educacional, consecuentemente, cae en el subjetivismo relativista, reduciendo la educación y su ciencia a un tema implicado en lo ideológico y lo axiológico, propiciando una tradición educativa centrada en la cuestión de los valores, en la idea de hombre y en los fines que éste realiza: la axiología, la antropología y la teleología limitarán y acotarán el campo del saber pedagógico. En definitiva, la teorización educativa se aleja de la realidad, perdiéndose con ello la posibilidad de una fundamentación autónoma y objetiva de la Pedagogía.

\section{TEORÍA EDUCATIVA Y HERENCIA HISTÓRICA}

Dos son los grandes posicionamientos o paradigmas desde los que se pretende abordar y conocer la realidad: el paradigma positivista (naturalista) y el paradigma crítico-hermenéutico (culturalista-espiritualista); cada uno se decanta por una metodología específica: método científico-experimental (naturalista) y método científico-racionalista (culturalista-espiritualista). Desde la concepción unitaria de la Pedagogía en Herbart hasta la emergencia de la etapa científica de principios del siglo xx, la Pedagogía se orientó, por una parte, hacia una Pedagogía de corte racionalista y filosófico (Pedagogía Racional) y otra, de corte científico, basada en la metodología experimental (Pedagogía Experimental). La cientificidad de la Pedagogía se fue debatiendo entre dos proyectos: erigirse como reflexión sobre los fines de la educación o constituirse como ciencia de medios y procedimientos que guiaran la acción educativa. La Pedagogía especulativa neokantiana alemana elaborada 
sobre los presupuestos epistemológicos de Windelband, Rickert y Dilthey ${ }^{19}$ optó por la reflexión finalística de lo educativo, dando lugar a una Pedagogía especulativa de marcado carácter filosófico, asentada entre las ciencias culturales y del espíritu, cuya misión era comprender e interpretar (teorizar) la fenomenología educacional. Por su parte, la Pedagogía positivista, científica y experimental se decantará por el segundo proyecto (practicar), desembocando, con el tiempo, en las llamadas ciencias de la educación entre las que aparecerá la Teoría de la Educación.

El afán experimentalista aspiraba a desarrollar un cuerpo unívoco de conocimientos sobre el hecho educativo y sobre los procesos de enseñanza-aprendizaje, lo cual debía facilitar el desarrollo de la Ciencia de la Educación, pues la investigación educacional abandonaría la línea histórico-filosófica que la Pedagogía había iniciado, y la Pedagogía Racional había desarrollado modernamente, con la pretensión de describir y explicar la fenomenología educativa (leyes generales) y deducir de dicho conocimiento científico los procedimientos y técnicas que pudieran regular de manera eficaz las prácticas de enseñanza (normas particulares). La Pedagogía se erigiría entonces en la Ciencia de la Educación por excelencia, aunque dependiente de otras ciencias auxiliares (visión científico-normativa y unitaria de la Pedagogía como ciencia autónoma de la educación). Es decir, la historia de la educación occidental se ha debatido entre pensar la educación y practicarla, creando, entre una y otra, un gran abismo: la disociación entre la preocupación y la ocupación.

A esta bifurcación paradigmática también hay que añadir las dificultades que se derivan de catalogar la ciencia pedagógica en función de la doble metodología utilizada: la experimental y la especulativa. A partir del primer tercio del siglo xx habrá una marcada tendencia a clasificar la ciencia pedagógica en función de su metodología y ubicaciones particulares (ciencias de la educación, de corte positivista), lo cual supondrá incrementar el confusionismo respecto a los fundamentos epistemológicos de la teoría educativa. La Pedagogía debe englobar las dos concepciones, la racional y la experimental, así como la utilización de cualquier método válido para la investigación educativa, ya que entre ambas, lejos de contradicción, existe complementación. El planteamiento racional de la educación puede y debe servir para definir nuevos planteamientos que siempre servirán para formular hipótesis de trabajo, que serán confirmadas o refutadas a través de la experimentación. De esta forma, el experimentalismo pedagógico puede clarificar las aportaciones realizadas desde el campo racional. De la conjunción de la especulación y la intervención surge el edificio unitario de la ciencia educacional. En Pedagogía no se dan dos tipos diferentes de conocimiento, sino dos fases o estadios de una misma ciencia. En definitiva, la construcción de una Ciencia de la Educación exige los esfuerzos conjuntos de ambas metodologías (saber para hacer).

19. A modo de ejemplo, ver los trabajos de los siguientes autores citados en la bibliografía: Hubert, Kriekemans, Redden y Ryan, Flitner, García Hoz, Göttler, Cohn, Lemus, Dilthey, Zaragüeta, Nassif. 
Sin embargo, superada ya esta etapa historicista, incluso hasta los primeros años setenta del siglo xx, aparecerán, al menos en España, innumerables obras con alguno de estos títulos: pedagogía general, pedagogía sistemática, pedagogía fundamental o pedagogía crítica, lo cual contribuirá a complicar aún más el proceso conceptualizador de la Teoría de la Educación ${ }^{20}$. En todas estas pedagogías (general, sistemática...) el contenido es eminentemente humanista al centrarse axiológicamente en el estudio del hombre y sus manifestaciones. La Pedagogía general es fundamental por su temática, sistemática por la ordenación estructurada de sus contenidos y crítica al estudiar al hombre. A partir del carácter humanista de la Pedagogía surge la imposibilidad de construir una teoría única de la educación, pues al fundamentarse en el hombre, concibe el pattern o modelo teleológico desde posiciones particulares, aspirando a la optimización del ser humano de acuerdo con un arquetipo axiológico previamente diseñado, cuya meta u objetivo se conseguirá mediante la actividad educacional. Como vemos, lo axiológico determina lo que se pretende estudiar, ya que es un modelo (perfectivo) apriorístico el que marca los objetivos, determinando así todas sus actuaciones. Será, consecuentemente, la pluridimensionalidad de modelos antropológico-axiológicos y la misión teleológica quienes dictarán las múltiples teorías que existen sobre la educación. Lo antropo-axio-teleológico es, pues, el condicionamiento de la relación educativa, ya que ésta, como hemos visto, siempre establece su evolución en función del modelo que se le presenta como meta o finalidad. De ahí que las teorias de la educación surjan con el afán de sistematizar los elementos educativos que se adecuan a la finalidad axiológica sobre la que se establece la educación (contexto ideológico o teorías de la educación), sin estudiar denotativamente el objeto primordial de toda Pedagogía, es decir, sin llegar, simple y llanamente, a la esencia de la educación y su fenomenología (Teoría de la Educación).

La gran dificultad epistemológica de la Pedagogía es consecuencia de su herencia histórica ${ }^{21}$, lo que equivale a decir que la problemática conceptual de la

20. Esta herencia ha continuado en España hasta nuestros días. Téngase en cuenta, por ejemplo, que el neotomismo sigue en plena vigencia en los años sesenta del siglo Xx, en las dos únicas especialidades de Pedagogía de la Universidad española, es decir, en Madrid y en Barcelona, a través de J. Zaragüeta, A. Pacios, A. Romero Marín y J. Tusquets. Por otra parte, en la década de los setenta será el personalismo de la Filosofía católica de J. Maritain o de L. Stefanini, quien intentará la sustitución moderna de los religionismos de antaño, y cuyos orígenes hay que buscarlos en los espiritualismos de autores como R. Eucken, T. Haecker, P. Wust o F. Ebner. En este sentido véase López QuiNTAS (1997).

21. Ante el protestantismo neoidealista generado, fundamentalmente, por la Escuela de Baden, y ante la tradición pestalozziana, la Iglesia católica propició una renovación de la escolástica de tal manera que ante el neoidealismo germánico pronto se opuso el neoescolasticismo (neotomismo) católico. El neoidealismo por una parte y el neoescolasticismo por otra, integraron lo pedagógico en el mundo religioso. Mientras las ciencias sociales avanzaban por diversos rumbos en la sociedad civil, la Pedagogía seguía sin salir del terreno religioso, incurriendo en una verdadera guerra de religión que pronto se alzó como la cuestión epistemológica de mayor envergadura. En esta línea podemos situar autores como $O$. Willmann, F. W. Foerster, F. de Hovre, J. H. Newman, R. Ruiz Amado, M. García Morente, J. Zaragüeta o J. Tusquets. 
educación, más que epistemológica, es histórica. Como hemos visto, desde distintos posicionamientos se empezó a confundir lo educativo con lo espiritual y con la idealización del hombre, lo que supuso que se abriera una pobre polémica, a lo largo de más de sesenta años (último tercio del siglo xxx y primer tercio del siglo $\mathrm{xx}$ ), sobre el saber educativa, que llevó a confundir argumentos y a crear una corriente subjetiva de pensamiento que tan sólo sirvió para alejar lo educacional de la realidad fáctica, situándose en la esfera de la especulación idealista, desligándose de la necesaria materialidad de la ciencia. Por otra parte, el pésimo y negativo trato que tanto el catolicismo como el protestantismo dieron a J. Dewey y su obra, ayudó notablemente a lastrar el pensamiento pedagógico: por una parte, el catolicismo propició una total marginación de Dewey, que era estudiado como uno más dentro de los autores propios de los manuales de Historia de la Educación, todos ellos realizados y monopolizados, como sabemos, por autores católicos (españoles o italianos); por otra parte, la filosofía alemana, mayoritariamente en manos de la Iglesia protestante, obvió la mención a Dewey (sobre todo por su radical biologicismo), negándonos el tan necesario debate entre los espiritualismos del neoidealismo germánico y la visión pragmática y utilitarista de la Pedagogía deweyana.

Sólo a partir de la atomización de las ciencias de la educación, que reemplazarán a la poco operante Pedagogía, los estudios pedagógicos van siendo tenidos en cuenta. La Pedagogía, orientada hacia las grandes trascendencias ontológicas, fue desentendiéndose de los verdaderos problemas educacionales, de la realidad -material- (social, cultural, política, psicológica...) de la educación, que, por el contrario, fue interesando a las demás ciencias humanas y sociales, que se apropiaron de su campo de estudio. ¿Y los valores? En tal contexto quedaron al dictado de la sociedad democrática, pero sin obligación de ser definidos en el ámbito de una disciplina científica. El fracaso del pensamiento acerca de lo pedagógico fue tan claro y de tal calibre que hizo que la Pedagogía se atomizase a manos del pragmatismo, el realismo y el materialismo aportado por las ciencias humanas y sociales en su aplicación al estudio de la educación. La historia de la construcción de la Pedagogía culminó, pues, con la desaparición de la propia Pedagogía, siendo sustituida por la Teoría de la Educación, que, ahora sí, pretende abordar el saber y el hacer acerca de lo educativo, configurándose entonces como una teoría para la acción educativa. Lo que no puede seguir reactualizándose — sin que algunos nos sorprendamos- es la afirmación de G. Gentile de que la Pedagogía es Filosofía. Hoy, la antigua Pedagogía, o teorización acerca de la educación, debe contemplar - como ya lo pretendiera Herbart (una de las bestias negras de Baden) y también Pestalozzi (idealista, no se olvide)—, "teorías de solución educativa" y no teorías de salvación mediante la educación". En este sentido acaso el idealismo de Baden haya sido la escuela de pensamiento que más lastre ha aportado a los estudios conceptuales de la educación al haber servido de freno histórico al desarrollo teórico de la educación.

Hemos querido pues evidenciar que la inmadurez epistemológica que sustenta o ha sustentado hasta ahora la teorización educativa tiene unos orígenes históricos 
- el neoidealismo de Baden- que hicieron de la Pedagogía una filosofía de segundo orden - subsidiaria - que ha tenido como objetivo dotarla de un sentido espiritual que le fue alejando de los fenómenos propios de la educabilidad. Su influencia, a lo largo de tantos años, ha ido lastrando a la Teoría de la Educación, que, por el contrario, debe fundamentarse en su realidad, que es fundamentalmente material, pues materiales son sus medios, sus espacios y biológicamente, materiales son sus protagonistas, con capacidad, eso sí, de desarrollar pensamiento abstracto, que está integrado en áreas y circuitos cerebrales concretos en función de niveles madurativos previamente alcanzados. Cuántas cosas nos tienen que enseñar aún las neurociencias a los que nos interesamos por la realidad educativa ${ }^{22}$.

Es decir, creemos que una teoría que tenga en cuenta cuáles - y de qué tiposon las realidades educativas, más aproximará el saber pedagógico a la solución de los problemas educativos; en cambio, las teorías filosóficas de la educación —sobre todo las idealistas - al ontologizar la educación alejaron a la Pedagogía de su realidad inmediata. Creemos firmemente que la Pedagogía podría haberse desarrollado de forma pareja a la Antropología, a la Psicología o a la Sociología, y si su evolución no fue así, no se debió a su identidad epistemológica, sino a las influencias de corte espiritualista, que brevemente hemos querido reflejar al inicio de este trabajo. Más diremos, sin la influencia de los espiritualismos de Baden, hoy no sería necesaria la Teoría de la Educación, pues la Pedagogía podría haberse desarrollado paralelamente a las otras ciencias sociales.

Es por ello que volvemos sobre nuestra afirmación primigenia para decir, efectivamente, que la problemática teórico-conceptual de la educación es más de corte histórico que no epistemológico. El suyo ha sido pues un problema genealógico.

De ahí que modelos como los cibernéticos, los sistémicos - y antes aun los organicistas, como los homeostáticos-y ahora, los asentados en la complejidad, en la neurociencia, y en las teorías caóticas, lo único que han pretendido ha sido abrir un espacio de debate para posibilitar una reactualización teórica acerca de la comprensión educativa, más allá de la filosofía, a caballo de las últimas tendencias de las ciencias sociales y de la naturaleza, buscando pues puntos de confluencia, a fin de aportar a la educación un discurso realista acerca de las soluciones a las problemáticas educativas. En el fondo, la crítica a Baden nos evidencia, aún con mayor rigor, que en educación las únicas teorías válidas son aquellas que sirven para solucionar problemas educativos. Si la Pedagogía no hubiese estado tan mediatizada por el idealismo espiritualista de corte neokantiano, hoy gozaría de una madurez teórica e investigadora acerca de su realidad que le hubiese propiciado una identidad y valoración social que a buen seguro sería, al día de hoy, de más alto nivel de la que ha tenido y sigue teniendo. Y ello, no es una afirmación en menoscabo de la Filosofía de la Educación que tiene su campo de estudio, su

22. Esta cuestión está más que insinuada en García Carrasco (2003), además de haberla defendido en foros y debates con claridad y fundamentación. Asimismo, véase AsENSIO (1997). 
interés y su papel a jugar en el mundo - en el mundo actual queremos decir - vistas las transformaciones de todo tipo que afectan a nuestras realidades. Nuestra crítica ha sido pues de corte historicista - lo que indujo al fracaso del saber pedagógico - si bien, por otra parte, nos ha ayudado aún más a delimitar los campos propios de la Filosofía de la Educación y de la Teoría de la Educación, siendo acaso la última conclusión que podemos extraer, la imposibilidad, cara al futuro, de que la Filosofía de la Educación vuelva a sustituir a los estudios teóricos acerca de la misma.

\section{BiBLIOGRAFÍA}

AsEnsio, J. M. (1997) Biologia y educación. Barcelona, Ariel.

BRIE, R. J. (2000) Vida, psicología comprensiva y hermenéutica: una revisión de categorías diltbeyanas. Pamplona, Servicio de Publicaciones de la Universidad de Navarra.

Bueno, G. (1978) Sobre la idea de la Cultura, La Nueva España, Oviedo, 25 de octubre.

CACCIATORE, G. (1993) Storicismo problemático e metodo crítico. Napoli, Guida.

CAMPS, V. (1993) Los valores de la educación. Madrid, Anaya.

CoHn, J. (1944) Pedagogia Fundamental. Buenos Aires, Editorial Losada.

Collingwood, R. G. (1956) The Idea of History. New York, Oxford University Press.

CuÉllar, H. (1998) Los valores, ¿existen?, en Paideia Twentieth World Congress of Philosophy, en Boston, Massachusetts, 10-15 agosto, 1998, http://www.bu.edu/wcp/MainValu.htm.

DACAL, J. A. (1995) Cultura y Filosofía, Logos, 67, enero-abril.

Díaz DE Cerio, F. (1957) El "espíritu objetivo" en W. Dilthey y su diferencia del "espíritu objetivo" en Hegel, Revista de Filosofia, 63, 547-565.

- (1961) Teoría pedagógica de W. Dilthey, Revista Española de Pedagogía, julio-septiembre, $255-272$.

DilTHEY, W. (1965) Fundamentos de un sistema de Pedagogía. Buenos Aires, Editorial Losada.

- (1968) Historia de la Pedagogía. Buenos Aires, Editorial Losada.

- (1978a) Introducción a las ciencias del espiritu. México, FCE.

- (1978b) Teoría de la concepción del mundo. México, FCE.

- (1978c) El mundo bistórico. México, FCE.

- (1978d) Psicología y teoría del conocimiento. México, FCE.

Dujovne, L. (1959) Teoría de los valores y filosofía de la bistoria. Buenos Aires, Piados.

EUCKEN, R. (1912) Las grandes corrientes del pensamiento contemporáneo. Madrid, D. Jorro edit.

- (1925) Der Kampf um einen Geistigen Lebensibalt Neu Grundlegung einer Weltauschauung. Berlín, Walter de Gruyter \& Co. (Versión castellana: [1925] La lucha por un contenido espiritual de la vida. Madrid, D. Jorro edit.).

FARRÉ, L. (1974) Antropología filosófica. Madrid, Guadarrama.

FEDERICI, F. (1933) La filosofía dei valori di Heinrich Rickert. Firenze, La nuova Italia.

FlamARIQue, L. (1991) La filosofía crítica o la hermenéutica de la razón vital, Cuadernos Salmantinos de Filosofia, XVIII, 153-163.

FutNer, W. (1935) Pedagogía Sistemática. Barcelona, Editorial Labor.

FRONDIZI, R. (1977) ¿Qué son los valores? Introducción a la axiología. México, FCE.

GABILONDO, A. (1988) Dilthey: vida, expresión e bistoria. Madrid, Cincel. 
GADAmER, H. G. (1988) Verdad y método. Salamanca, Ediciones Sígueme.

GARCía CARRASCO, J. (2003) Evolución del contexto social y cambios en el pensamiento sobre la educación. Educación por la influencia o educación desde la experiencia, en Seminario Interuniversitario de Teoría de la Educación: Teoría de la Educación, ayer y boy. Murcia, 57-107.

García Hoz, V. (1985) Principios de Pedagogía sistemática. Madrid, Rialp.

GÖTtLER, J. (1955) Pedagogía sistemática. Barcelona, Herder.

Grondin, J. (1989) Kant et le problème de la philosophie: l'a priori. Paris, Librairie Philosophique J. Vrin.

HEGEL, W. G. (1935) La fenomenología del espiritu. Madrid, Revista de Occidente.

HenZ, H. (1976) Tratado de Pedagogía sistemática. Barcelona, Herder.

HuberT, H. (1976) Tratado de Pedagogía sistemática. Barcelona, Herder.

HuberT, R. (1990) Tratado de Pedagogía general. Buenos Aires, El Ateneo.

IMAZ, E. (1978) El pensamiento de Dilthey. México, FCE.

Kriekemans, A. (1982) Pedagogia general. Barcelona, Herder.

LARroyo, F. (1942) La filosofía de los valores. México, Porrúa.

LEDESMA, R. (1982) De Rickert a la Fenomenología, en La filosofía, disciplina imperial. Madrid, Tecnos.

Lemus, L. A. (1973) Pedagogía. Temas fundamentales. Buenos Aires, Kapelusz.

López Moreno, A. (1990) Comprensión e interpretación en las ciencias del espíritu. Murcia, Universidad de Murcia.

LÓPEz QuiNTAS, A. (1989) El conocimiento de los valores. Estella (Navarra), Verbo Divino.

- (1997) El poder del diálogo y del encuentro. Madrid, BAC.

LOSEE, J. (1989) Filosofía de la ciencia e investigación bistórica. Madrid, Alianza.

Mallorquín, C. (1999) Metodología o Ciencia Social, Cinta de Moebio. Revista Electrónica de Epistemología de Ciencias Sociales, $\mathrm{n}^{\circ}$ 6, septiembre.

MARDONES, J. M. ${ }^{\mathrm{a}}$ y URSUA, N. (1982) Filosofía de las ciencias humanas y Sociales: materiales para una fundamentación científica. Barcelona, Fontamara.

Marías, J. (1944) Teoria de las concepciones del mundo. Madrid, Revista de Occidente.

Messer, A. (1933) Fundamentos Filosóficos de la Pedagogía. Barcelona, Editorial Labor.

Moncho, J. R. (2003) Teoría de los valores superiores. Valencia, Campgràfic.

MoYa Espí, C. (1982) Interacción y configuración en el pensamiento de Dilthey. Madrid, Fundación Juan March.

NASSIF, R. (1987) Pedagogía general. Madrid, Cincel.

NAVARRO, U. (1962) Teoría de los valores histórico-sociales: crítica y método bistórico. Quito, Universidad Nacional.

NoHL, H. (1965) Antropología Pedagógica. México, FCE.

OrTega y GASSET, J. (1923) Qué son los valores, Revista de Occidente, 4, 39-70. También en Obras Completas, VI, 315-335.

- (1927) Vitalidad, alma, espíritu, en El Espectador, V. Madrid, Revista de Occidente.

- (1933-1934) Guillermo Dilthey y la idea de la vida, Revista de Occidente, 42, 197-214 y 43, 89-112.

PÁEz Galín, F. (1988) El concepto de comprensión en W. Dilthey. Madrid, Universidad Complutense.

REDDEN, D. y RYAN, F. A. (1967) Pedagogía general y Filosofía de la Educación. Madrid, Morata. 
ANTONIO J. COLOM CAÑELLAS Y JUAN C. RINCÓN VERDERA EPISTEMOLOGÍA NEOIDEALISTA Y FRACASO FUNDACIONAL DEL SABER EDUCATIVO

RICKERT, H. (1910) Kulturwissenschaft und Naturwissenschaft. (Edición en castellano: [1965] Ciencia cultural y ciencia natural. Madrid, Espasa-Calpe).

RickerT, H. (1915) Zur Lebre von der Definition. Tübingen, Mohr. (Edición en castellano: [1960] Teoría de la definición. México, Centro de Estudios Filosóficos de la Universidad Nacional Autónoma).

Rose, G. (1991) Hegel Contra Sociology. Londres, Athelone.

RUGER, R. (1969) La filosofía del valor. México, FCE.

SCHELLER, M. (1941-1942) Ética. Nuevo ensayo de fundamentación de un personalismo ético. Madrid, Revista de Occidente (2 vols.).

SCHNÄDELBACH, H. (1991) Filosofia en Alemania (1883-1933). Madrid, Cátedra.

SCHRÖRDINGER (1956) Mind and matter. London, The Tarner lectures.

SCHUWERAR, W. G. (1933) La esencia del valor y su fundamentación. Buenos Aires, Verbum SPRANGER, E (1923) Rickert's system, Logos, 12.

- (1948) Psicología de la edad juvenil. Buenos Aires, Revista de Occidente.

SteFanovics, T. (1961) Dilthey, una filosofía de la vida. Montevideo, Editorial Bibliográfica Uruguay.

TUTTLE, H. N. (1994) The dawn of historical reason: the bistoricality of buman existence in the thought of Dilthey, Heidegger and Ortega y Gasset. New York, Lang, cop.

WindelBand, W. (1903) Präludien: Aufsätze und Reden zur Einfubrung in die Philosophie. Tübingen, Verlag v J.C.B. Mohr. (Edición en castellano: [1949] Preludios filosóficos: figuras y problemas de la filosofía y de su bistoria. Buenos Aires, Santiago Rueda).

- (1910) Kultur-philosophie und transzcendentaler idealisms, Logos, 1, 186-196.

- (1947) La scienze naturali e la Storia, en Preludi. Saggi e Discorsi d'Introduzione alla Filosofia. Milano, Valentino Bompiani, 156-174.

- (1960) Historia general de la filosofía. Barcelona, El Ateneo.

ZARAGÜETA, J. (1953) Pedagogía fundamental. Barcelona, Labor.

APÉNDICE BIBLIOGRÁFICO

a. Bibliografía especifica de Windelband:

- (1903) Präludien: Aufsätze und Reden zur Einfubrung in die Philosophie. Tübingen, Verlag v J.C.B. Mohr. (Edición en castellano: [1949] Preludios filosóficos: figuras y problemas de la filosofia y de su bistoria. Buenos Aires, Santiago Rueda).

- (1910) Kultur-philosophie und transzcendentaler idealisms, Logos, 1, 186-196.

- (1947) La scienze naturali e la Storia, en Preludi. Saggi e Discorsi d'Introduzione alla Filosofia. Milano, Valentino Bompiani, 156-174.

- (1960) Historia general de la filosofía. Barcelona, El Ateneo.

\section{b. Bibliografia sobre Windelband:}

Bonito, R. (1990) Il compito della filosofia: saggio su Windelband. Napoli, Morano. Heimsoeth, H. (1960) Historia general de la filosofía. México, El Ateneo. Rossi, P. (1972) Lo storicismo contemporäneo. Torino, Loescher. Rosso, C. (1973) Figure e dottrine della filosofia dei valori. Napoli, Guida.

VV.AA. (2000) Néokantismes et théorie de la connaissance. Paris, Librairie Philosophique J. Vrin. 
ANTONIO J. COLOM CAÑELLAS Y JUAN C. RINCÓN VERDERA

EPISTEMOLOGÍA NEOIDEALISTA Y FRACASO FUNDACIONAL DEL SABER EDUCATIVO

c. Bibliografía específica de Rickert:

- (1903) Die Grenzen der naturwissenschaftlichen Begriffsbildung: eine logische Einleitung in die historischen Wissenschaften. Tübingen, Mohr. (Edición en inglés: [1986] The limits of concept formation in natural science logical introduction to the bistorical sciences. Cambridge: Cambridge University Press).

- (1907) Die Probleme der Geschichtsphilosophie. Tübingen, Mohr. (Edición en castellano: [1961] Introducción a los problemas de la filosofia de la bistoria. Buenos Aires, Nova).

- (1910) Kulturwissenschaft und Naturwissenschaft. Tübingen, Mohr. (Edición en castellano: [1965] Ciencia cultural y ciencia natural. Madrid, Espasa-Calpe).

- (1915) Zur Lebre von der Definition. Tübingen, Mohr. (Edición en castellano: [1960] Teoria de la definición. México, Centro de Estudios Filosóficos de la Universidad Nacional Autónoma).

- (1924) Kant als Pbilosoph der modernen Kultur: ein geschichtsphilosopbischer Versuch. Tübingen, Mohr.

- (1934) Grundprobleme der philosophie: methodologie, ontologie, anthropologie. Tübingen, Mohr.

\section{d. Bibliografia sobre Rickert:}

KRIJNEN, C. (2001) Nachmetaphysischer Sinn: eine problemgesichichtliche und systematische Studie zu den Prinzipien der Wertpbilosophie Heinrich Rickert. Würzburg, Königshausen \& Neumann.

OAKES, G. (1988) Weber and Rickert concept formation in the cultural sciences. Cambridge, Mass., London.

Ramming, G. (1948) Karl Jaspers und Heinrich Rickert: Existenzialismus und Wertphilosophie. Bern, A. Francke.

RAVÀ, A. (1990) Il valore della storia: di fronte alle scienze naturali e per la concezione del mondo. Roma, Lavoro.

Rossi, P. (1972) Lo storicismo contemporàneo. Torino, Loescher.

Rosso, C. (1973) Figure e dottrine della filosofia dei valori. Napoli, Guida.

VV.AA. (2000) Néokantismes et théorie de la connaissance. Paris, Librairie Philosophique J. Vrin.

\section{e. Bibliografía específica de Dilthey:}

Obra completa en alemán (no acabada). (1914ss) Gesammelte Schriften, 21 vols. StuttgartGöttingen, Vandenhoeck\&Ruprecht: Vol. I. Einleitung in die Geisteswissenschaften. Versuch einer Grundlegung für das Studium der Gesellschaft und der Geschichte. Vol. II. Weltanschauung und Analyse des Menschen seit Renaissance und Reformation. Vol. III. Studien zur Geschichte des deutschen Geistes Leibniz und sein Zeitalter. Friedrich der Grosse und die deutsche Aufklärung. Das achtzehnte Jahrhundert und die geschichtliche Welt. Vol. IV. Die Jugendgeschichte Hegels und andere Abhandlungen zur Geschichte des Deutschen Idealismus. Vol. V. Die geistige Welt. Einleitung in die Philosophie des Lebens (Abhandlungen zur Grundlegung der Geisteswissenschaften). Vol. VI. Die geistige Welt. Einleitung in die Philosophie des Lebens (Abhandlungen zur Poetik, Ethik und Pädagogik). Vol. VII. Der Aufbau der geschichtlichen Welt in den Geisteswissenschaften. Vol. VIII. Weltanschauungslehre. Abhandlungen zur Philosophie der 
Philosophie. Vol. IX. Pädagogik. Geschichte und Grundlinien des Systems. Vol. X. System der Ethik. Vol. XI. Vom Aufgang des geschichtlichen Bewusstseins. Jugendaufsätze und Erinnerungen. Vol. XII. Zur preussischen Geschichte. Schleiermachers politische Gesinnung und Wirksamkeit. Die Reorganisatoren des preussischen Staates. Das allgemeine Landrecht. Vol. XIII. Leben Schleiermachers. Erster Band. 1. Halbband: 17681802, 2. Halbband: 1803-1807 Aufgrund d. Textes d. 1. Vol. XIV. Leben Schleiermachers. Zweiter Band: Schleiermachers System als Philosophie und Theologie. 1. Halbband: Schleiermachers System als Philosophie. 2. Halbband: Schleiermachers System als Theologie. Vol. XV. Zur Geistesgeschichte des 19. Jahrhunderts. Portraits und biographische Skizzen. Quellenstudien und Literaturberichte zur Theologie und Philosophie im 19. Jahrhundert. Vol. XVI. Zur Geistesgeschichte des 19. Jahrhunderts. Aufsätze und Rezensionen aus Zeitungen und Zeitschriften. 1859-1874. Vol. XVII. Zur Geistesgeschichte des 19. Jahrhunderts. Aus "Westermanns Monatsheften": Literaturbriefe, Berichte zur Kunstgeschichte, Verstreute Rezensionen 1867-1884. Vol. XVIII. Die Wissenschaften vom Menschen, der Gesellschaft und der Geschichte. Vorarbeiten zur Einleitung in die Geisteswissenschaften (1865-1880). Vol. XIX. Grundlegung der Wissenschaften vom Menschen, der Gesellschaft und der Geschichte Ausarbeitungen und Entwürfe zum zweiten Band der Einleitung in die Geisteswissenschaften (ca. 1870-1895). Vol. XX. Logik und System der philosophischen Wissenschaften. Vorlesungen zur erkenntnistheoretischen Logik und Methodologie (1864-1903). Vol. XXI. Psychologie als Erfahrungswissenschaft. Erster Teil: Vorlesungen zur Psychologie und Anthropologie (ca. 1875-1894). Vol. XXII. Psychologie als Erfahrungswissenschaft. Zweiter Teil: Manuskripte zur Genese der deskriptiven Psychologie (ca. 1880-1896). Vol. XXIII. Allgemeine Geschichte der Philosophie. Vorlesungen 1900-1905.

Obra completa en castellano (acabada). (1978) Obras de Wilhelm Dilthey. Traducción de Eugenio Imaz, 10 vols. México, FCE.: Vol. I: Introducción a las ciencias del espíritu. Vol. II: Hombre y mundo en los siglos xvi y xvir. Vol. III: De Leibniz a Goethe. Vol. IV: Vida y poesía. Vol. V: Hegel y el idealismo. Vol. VI: Psicología y teoría del conocimiento (contiene entre otras cosas las "Ideas acerca de una psicología descriptiva y analítica") (1894). Vol. VII: El mundo histórico. Vol. VIII: Teoría de la concepción del mundo. Vol. IX: Literatura y fantasía. Vol. X: Historia de la Filosofía.

\section{f. Bibliografia sobre Dilthey:}

Amengual, G. (1996) Der Geschichte der Philosophie und ihr kultureller Kontext. Hegel und Dilthey, Hegel-Jabrbuch 1995, Berlin, 69-74.

ARreGUi, J. V. (1988) Metafísica del yo y hermenéutica diltheyana de la vida, Anuario Filosófico, 21 (1), 97-119.

BaumgarTner, H. M. (1972) Kontinuität und Geschichte. Zur Kritik und Metakritik der historischen Vernunft. Frankfurt, A. M.

BiAnco, F. (1971) Dilthey e la genesi della critica storica della ragione. Milano, Marzorati.

- (1985) Introduzione a Dilthey. Roma-Bari, Laterza.

BRogowsky, L. (1997) Dilthey, conscience et bistoire. Paris, Presse Universitaires de France.

CACCIATORe, G. (1976) Scienza e filosofia in Diltbey. Napoli, Guida.

- (1985) Vita e forme della scienza storia. Saggi sulla storiografia di Dilthey. Napoli, Guida.

CHoza, J. (1976) Hábito y espíritu objetivo. Estudio sobre la historicidad de Santo Tomás y en Dilthey, Anuario Filosófico, 9, 11-71. 
CRistin, R. (2000) Fenomenología de la bistoricidad: el problema de la bistoria en Dilthey y Husserl. Madrid, Akal.

Díaz de CERIO, F. (1959) W. Dilthey y el problema del mundo histórico. Estudio genético-evolutivo, con una bibliografía general. Barcelona, Juan Flors.

- (1963) Introducción a la filosofía de W. Dilthey. Barcelona, Juan Flors.

FERNÁNDEZ, F. (2001) La antropología de Wilbelm Dilthey. Roma, Apollinare Studi.

GRONDIN, J. (1991) Einfübrung in die philosophische Hermeneutik. Darmstadt, WBG.

HABERMAS, J. (1987) Coneixemenent i interés. Barcelona, Edicions 62.

INNEICHEN, H. (1975) Erkenntnistheorie und geschichtlich-gesellschaftliche Welt. Diltheys Logik der Geisteswissenschaften. Frankfurt, Suhrkamp.

LÓPEZ, A. (1990) Comprensión e interpretación en las ciencias del espiritu: W. Dilthey. Murcia, Universidad de Murcia.

MAGER, K. (1982) Pbilosophie als Funktion. Studien zu Diltheys Schrift 'Das Wesen der Philosopbie. Würzburg, Königshausen\&Neumann.

Makkreel, R. A. (1992) Dilthey: philosopher of the buman studies. Princeton, Princeton University Press.

MARALDO, J. C. (1984) Der hermeneutische Zirke: Untersuchungen zu Schleiermacher, Dilthey und Heidegger. Freiburg, K. Alber.

MARINI, G. (1965) Dilthey e la compresione del mondo umano. Milano, Dott. A. Giuffrè.

MateuCCI, G. (1995) Immagini della vida. Logica ed estetica a partire da Dilthey. Bologna, Clueb.

MeSURE, S. (1990) Dilthey et la fondation des sciences historiques. Paris, PUF.

MoYA, C. (1982) Interacción y configuración en el pensamiento de Dilthey. Madrid, Fundación J. March.

Ortega y GaSSET, J. (1983) Guillermo Dilthey y la idea de la vida, en Obras completas. Madrid, Alianza, 165-214.

PÁez Galín, F. (1988) El concepto de comprensión en W. Dilthey. Madrid, Universidad Complutense.

Roura-Parella, J. (1946) Conceptos fundamentales del pensamiento de Dilthey. La Habana, Universidad de La Habana.

- (1947) El mundo bistórico social: ensayo sobre la morfologia de la cultura de Diltbey. México, Instituto de Investigaciones Sociales.

RÜTSCHE, J. (1999) Das Leben aus der Schrift versteben: Wilbelm Diltheys bermeneutik. Bern, Lang.

TREJO, W. (1962) Introducción a Dilthey. Xapala, Veracruz, Universidad Veracruzana.

ZÖCKLER, Ch. (1975) Dilthey und die Hermeneutik. Diltheys Begründung der Hermeneutik als Praxiswissenschaft und die Geschichte ibrer Rezeption. Stuttgart, Metzler. 